\title{
The impact of down-regulation on obstetrics and perinatal outcomes in singleton pregnancies after IVF: a retrospective cohort study
}

\section{Xiyuan Dong}

Tongji Hospital of Tongji Medical College of Huazhong University of Science and Technology

\section{Yu Zheng}

Tongji Hospital of Tongji Medical College of Huazhong University of Science and Technology

\section{Biao Chen}

Tongji Hospital of Tongji Medical College of Huazhong University of Science and Technology

\section{Lan Wang}

Tongji Hospital of Tongji Medical College of Huazhong University of Science and Technology

\section{Lei Jin}

Tongji Hospital of Tongji Medical College of Huazhong University of Science and Technology Jihui Ai ( $\nabla$ jihuiai@tjh.tjmu.edu.cn )

Tongji Hospital of Tongji Medical College of Huazhong University of Science and Technology

\section{Research article}

Keywords: down-regulation, obstetrics outcomes, perinatal outcomes, singleton pregnancy, IVF

Posted Date: July 7th, 2020

DOI: https://doi.org/10.21203/rs.3.rs-40379/v1

License: (c) (i) This work is licensed under a Creative Commons Attribution 4.0 International License. Read Full License 


\section{Abstract}

Background Down-regulation has been widely used in IVF treatment; however, it lacks reports on the impact of down-regulation on obstetrics and perinatal outcomes. The purpose of this study is to evaluate the effect of down-regulation on obstetrics and perinatal outcomes. Methods This is a retrospective cohort study on 3578 patients achieving singleton pregnancy after their first IVF attempt. The patients were grouped by the serum estradiol after down-regulation (E2D) into three groups: $<30,30-55,>55 \mathrm{pg} / \mathrm{ml}$. The cumulative live-birth rate, obstetrics and pediatric results were main outcome measures. General linear models and Chi-square test were performed for statistical analysis. Results The patients with E2D $<30,30-55,>55 \mathrm{pg} / \mathrm{ml}$ had similar cumulative live-birth rate. The patients with E2D $<30 \mathrm{pg} / \mathrm{ml}$ had a lower risk for hypertension disorders than those with E2D 30-55pg/ml. No difference was found in the prevalence of placenta previa, placenta abruption, premature rupture of membrane, hemorrhage, gestational diabetes mellitus, or intrauterine growth restriction. The newborns of patients with E2D $<30 \mathrm{pg} / \mathrm{ml}$ had a lower risk for PICU attempt than those with E2D $>55 \mathrm{pg} / \mathrm{ml}$. There was no difference in congenital anomaly or mortality rate. Conclusion We found no effect of down-regulation on cumulative live-birth rate. The patients with E2D<30 pg/ml may have advantages in lower risks for maternal hypertension and newborns PICU attempt.

\section{Background}

Pituitary down-regulation with a gonadotropin-releasing hormone-agonist ( $\mathrm{GnRH}-\mathrm{a})$ is a common practice in the field of In Vitro Fertilization (IVF). Down-regulation can avoid premature luteinizing hormone surge, favor follicle development, synchronize the growth of follicles and endometrium, and thus improve IVF success (1). In addition, down-regulation also has an advantage in treatment scheduling. Previous studies have shown the superiority of down-regulation, in terms of a lower cycle cancelation rate and a higher pregnancy rate (2). Our previous study showed that the degree of down-regulation was associated with the outcomes of ovarian response, pregnancy, and live birth. A serum estradiol level after downregulation (E2D) $<55 \mathrm{pg} / \mathrm{ml}$ is an optimal status for subsequent pregnancy (3).

It is estimated that births after IVF is over $1 \%$ of all births in the UK (4). There is a growing concern about the safety of IVF, in terms of obstetrics and perinatal outcomes (5-7). It has been reported that IVF increased risks for maternal disorders, e.g. placenta accreta, hypertensive disorders, and psychological disorders $(5,8,9)$. Besides, it has been shown that IVF was associated with preterm birth, low birth weight, gender bias (10-12), and congenital anomalies (13).

To our knowledge, there is a lack of study analyzing IVF safety in different down-regulation conditions. The objective of this study is to evaluate whether there is an association between down-regulation and obstetrics/perinatal outcomes in singleton pregnancies after IVF.

\section{Methods}




\section{Study population}

This is a retrospective cohort study on the patients undergoing their first IVF treatment at our center, between January 2009 and December 2013. Inclusion criteria: (1) patients undergoing standard midluteal phase $\mathrm{GnRH}$-a long protocol; (2) patients who achieved clinical pregnancy after their first stimulated cycle (fresh and/or subsequent frozen embryo transfer). Exclusion criteria: (1) patients involving donation or freezing of gemmates; (2) patients undergoing PGD/PGS; (3) patients with hypertension, diabetes mellitus or immune diseases. All patients were followed up to the termination of pregnancy. Finally, the data of a total of 3578 patients were extracted for analyses. This study was conducted with the formal approval of the Institution Review Board (IRB) of Tongji Hospital. All patients in this study have given written consent to the inclusion of material pertaining to them. They have been fully anonymized before analysis.

\section{Clinical protocols}

Down-regulation, ovarian stimulation, IVF, embryo culturing, and embryo transfer were performed as previously published (3). Briefly, a daily injection of $0.1 \mathrm{mg} \mathrm{GnRH}-\mathrm{a}$ (Decapeptyl, Ferring, Switzerland or Diphereline, Ipsen, Australia) was initiated in the midluteal-phase of the preceding cycle. The ovarian stimulation with gonadotropins was initiated with rFSH (Gonal-F, Serono, Switzerland or Puregon, Organon, Netherlands). The starting dose of gonadotropin was 150-225 IU/d based on the age, antral follicle count (AFC), basal FSH, and body mass index (BMI). The dosage of $\mathrm{GnRH}$-a was then reduced to $0.05 \mathrm{mg} /$ day till the day of hCG triggering. The gonadotropin dose was adjusted according to the ovarian response, which is assessed by serum E2, progesterone $(\mathrm{P}), \mathrm{LH}$, and serial ultrasound scans. When at least 2-3 follicles developed to a diameter of $\geq 18 \mathrm{~mm}, 10,000 \mathrm{IU}$ hCG was given to trigger the maturation of follicles. Oocytes were retrieved transvaginally 36-38 hours after the hCG injection. The fertilization method included IVF and ICSI. In a fresh cycle, typically no more than two best-quality embryos were transferred on day 3 after oocyte retrieval, and excessive available embryos were cryopreserved for subsequent FET cycles. An administration of $60 \mathrm{mg} P$ was used as luteal phase support from the day of oocyte retrieval. The protocol for blastocyst culture, embryo vitrification and warming, and FET have been described in the previously published literature (14).

\section{Outcome measures}

The primary measures were maternal and perinatal outcomes. The results of ovarian stimulation and pregnancy were also analyzed. A clinical pregnancy was diagnosed when the serum hCG level reached > $20 \mathrm{IU} / \mathrm{I}$ two weeks after transfer and the gestational sac was detected on ultrasound 5-7 weeks after transfer. A live birth was defined as the completion of expulsion or the extraction of a live baby after 28th gestational week (15). 


\section{Grouping of patients with E2D}

Patients were classified into the over (E2D $<30 \mathrm{pg} / \mathrm{ml}$ ), optimal (E2D $30-55 \mathrm{pg} / \mathrm{ml}$ ), and insufficient (E2D $>55 \mathrm{pg} / \mathrm{ml}$ ) down-regulated group, according to the criteria published in our previous study (3).

\section{Statistical analysis}

SAS 9.2 (SAS, Inc., Cary, NC, USA) was used for statistical analysis. Numeric parameters were presented as mean \pm SD. Categorical variables were presented as percentage (number). General linear models and Chi-square test were performed appropriately. Multiple comparisons were performed with Turkey or Bonferroni method. A $P$ value $<0.05$ was considered statistically significant.

\section{Results}

The data from a total of 3578 patients were analyzed. The demographic and clinical characteristics are shown in Table 1. There were differences in the age, BMI, baseline serum FSH level and AFC among the patients with E2D $<30,30-55$ and $>55 \mathrm{pg} / \mathrm{ml}$, but these differences are very slight and of no clinical value. The duration and type of infertility were similar among the three groups. 
Table 1

The demographic and clinical characteristics

\begin{tabular}{|lllll|}
\hline & E2D $<30 \mathrm{pg} / \mathrm{ml}$ & E2D 30-55 pg/ml & E2D $>55 \mathrm{pg} / \mathrm{ml}$ & $P$ value \\
\hline No. of patients & 1523 & 1677 & 378 & \\
\hline Age (years) & $30.4 \pm 4.1$ & $29.9 \pm 4.0$ & $30.1 \pm 4.0$ & $<0.01^{\mathrm{a}}$ \\
\hline BMI (kg/m $\left.{ }^{2}\right)$ & $21.2 \pm 2.6$ & $21.6 \pm 2.9$ & $22.2 \pm 3.1$ & $<0.01^{\mathrm{abc}}$ \\
\hline Duration of infertility (years) & $4.6 \pm 3.2$ & $4.5 \pm 3.2$ & $4.8 \pm 3.4$ & $\mathrm{NS}$ \\
\hline Type of infertility (\%) & & & $47.1(178 / 378)$ & NS \\
\hline Primary infertility & $49.2(749 / 1523)$ & $45.8(768 / 1677)$ & $52.9(200 / 378)$ & \\
\hline Secondary infertility & $50.8(774 / 1523)$ & $54.2(909 / 1677)$ & $5.7 \pm 1.8$ & $<0.01^{\mathrm{abc}}$ \\
\hline Basal FSH level (mIU/ml) & $6.4 \pm 1.9$ & $6.1 \pm 1.9$ & $16.8 \pm 6.9$ & $<0.01^{\mathrm{abc}}$ \\
\hline Basal AFC & $14.3 \pm 5.4$ & $15.3 \pm 5.8$ & & \\
\hline Note: & & & \\
\hline FSH: follicle stimulating hormone; AFC: antral follicle count & \\
\hline a: a significant difference between the group of E2D $<30$ and $30-55 \mathrm{pg} / \mathrm{ml} ;$ & \\
\hline b: a significant difference between the group of E2D $<30$ and $>55 \mathrm{pg} / \mathrm{ml} ;$ & \\
\hline c: a significant difference between the group of E2D $30-55$ and $>55 \mathrm{pg} / \mathrm{ml} ;$ & \\
\hline NS: not significant & & & \\
\hline
\end{tabular}

Table 2 shows the ovarian stimulation parameters and pregnancy outcomes. The patients with E2D > $55 \mathrm{pg} / \mathrm{ml}$ had lower dosage of stimulation compared with those with E2D $<30 \mathrm{pg} / \mathrm{ml}(25.9 \pm 7.9 \mathrm{vs} .29 .0$ \pm 6.8 ampules, $P<0.01)$. The serum peak E2 level in the patients with E2D $<30 \mathrm{pg} / \mathrm{ml}$ was lower compared with those with E2D $30-55 \mathrm{pg} / \mathrm{ml}$ and $>55 \mathrm{pg} / \mathrm{ml}(4982.9 \pm 2792.9$ vs. $5471.7 \pm 2890.8$ and $5623.6 \pm 2614.2 \mathrm{pg} / \mathrm{ml}, P<0.01)$. The differences in the duration of $\mathrm{rFSH}$, number of oocytes retrieved and number of good embryos have limited clinical value. The serum $\mathrm{P}$ level was similar among the three groups. The patients with E2D $<30,30-55$ and $>55 \mathrm{pg} / \mathrm{ml}$ obtained similar live-birth rate and miscarriage rate. Regarding the obstetrics outcomes, the patients with E2D $<30 \mathrm{pg} / \mathrm{ml}$ had a lower risk for hypertension disorders compared with those with E2D $30-55 \mathrm{pg} / \mathrm{ml}(0.46 \% \mathrm{vs} .1 .31 \%, P=0.04)$. The risks for placenta previa, placenta abruption, premature rupture of membrane, hemorrhage, gestational diabetes mellitus and intrauterine growth restriction were similar among the three groups. 
Table 2

The ovarian performance and pregnancy outcomes

\begin{tabular}{|c|c|c|c|c|}
\hline & $\mathrm{E} 2 \mathrm{D}<30 \mathrm{pg} / \mathrm{ml}$ & E2D $30-55$ pg/ml & $\mathrm{E} 2 \mathrm{D}>55 \mathrm{pg} / \mathrm{ml}$ & $P$ value \\
\hline No. of patients & 1523 & 1677 & 378 & \\
\hline Duration of rFSH (days) & $10.2 \pm 1.5$ & $10.1 \pm 1.6$ & $9.6 \pm 1.5$ & $<0.01^{b c}$ \\
\hline Dosage of rFSH (ampules) & $29.0 \pm 6.8$ & $27.0 \pm 4.5$ & $25.9 \pm 7.9$ & $<0.01^{\mathrm{b}}$ \\
\hline Serum E2 level (pg/ml) & $4982.9 \pm 2792.9$ & $5471.7 \pm 2890.8$ & $5623.6 \pm 2614.2$ & $<0.01^{\mathrm{ab}}$ \\
\hline Serum P level (ng/ml) & $1.3 \pm 0.8$ & $1.3 \pm 0.7$ & $1.4 \pm 0.6$ & NS \\
\hline No. of oocytes retrieved & $14.2 \pm 6.9$ & $15.2 \pm 7.1$ & $15.6 \pm 7.6$ & $<0.01^{\mathrm{ab}}$ \\
\hline No. of good embryos & $5.8 \pm 3.5$ & $6.1 \pm 3.4$ & $6.4 \pm 4.2$ & $<0.01^{\mathrm{b}}$ \\
\hline Live birth rate (\%) & $82.6(1258 / 1523)$ & $82.8(1388 / 1677)$ & $79.9(302 / 378)$ & NS \\
\hline Miscarriage rate (\%) & $17.4(265 / 1523)$ & $17.2(289 / 1677)$ & $20.1(76 / 378)$ & NS \\
\hline \multicolumn{5}{|l|}{ Maternal outcomes } \\
\hline Hypertension (\%) & $0.46(7 / 1523)$ & $1.31(22 / 1677)$ & $0.79(3 / 378)$ & $0.04^{\mathrm{a}}$ \\
\hline Placenta previa (\%) & $0.72(11 / 1523)$ & $0.36(6 / 1677)$ & $0.53(2 / 378)$ & NS \\
\hline Placenta abruption (\%) & $0.07(1 / 1523)$ & $0.06(1 / 1677)$ & - & NS \\
\hline PROM (\%) & $0.98(15 / 1523)$ & $1.55(26 / 1677)$ & $1.32(5 / 378)$ & NS \\
\hline Hemorrhage (\%) & $0.13(2 / 1523)$ & $0.36(6 / 1677)$ & $0.53(2 / 378)$ & NS \\
\hline GDM (\%) & $0.13(2 / 1523)$ & $0.24(4 / 1677)$ & $0.26(1 / 378)$ & NS \\
\hline FGR (\%) & $0.33(5 / 1523)$ & $0.18(3 / 1677)$ & $0.26(1 / 378)$ & NS \\
\hline ICP (\%) & $0.07(1 / 1523)$ & $0.12(2 / 1677)$ & $0.26(1 / 378)$ & NS \\
\hline \multicolumn{5}{|l|}{ Note: } \\
\hline \multicolumn{5}{|c|}{$\begin{array}{l}\text { rFSH: recombinant follicle stimulating hormone; E2: estradiol; P: progesterone; PROM: premature } \\
\text { rupture of membranes; GDM: gestational diabetes mellitus; FGR: fetal growth restriction; ICP: } \\
\text { intrahepatic cholestasis of pregnancy }\end{array}$} \\
\hline \multicolumn{5}{|c|}{ a: a significant difference between the group of E2D $<30$ and $30-55 \mathrm{pg} / \mathrm{ml}$; } \\
\hline \multicolumn{5}{|c|}{ b: a significant difference between the group of E2D $<30$ and $>55 \mathrm{pg} / \mathrm{mll}$; } \\
\hline \multicolumn{5}{|c|}{ c: a significant difference between the group of E2D $30-55$ and > $55 \mathrm{pg} / \mathrm{ml}$; } \\
\hline NS: not significant & & & & \\
\hline
\end{tabular}


The newborns outcomes are shown in Table 3 and Fig. 1. The mean gestational week, percentage of preterm birth and very preterm birth were similar among the patients with E2D $<30,30-55$ and > $55 \mathrm{pg} / \mathrm{ml}$. No differences were found in the mean birth weight, percentage of low birth weight and very low birth weight. The newborns from the group of E2D $<30 \mathrm{pg} / \mathrm{ml}$ had a lower risk for attending PICU (Pediatric Intensive Care Unit) compared with those of E2D $>55 \mathrm{pg} / \mathrm{ml}(2.1 \%$ vs. $4.6 \%, P=0.04)$. There were no differences in the prevalence of congenital malformation and mortality among the three groups.

Table 3

The perinatal outcomes

\begin{tabular}{|lllll|}
\hline & E2 $<30 \mathrm{pg} / \mathrm{ml}$ & E2D 30-55 pg/ml & E2D $>\mathbf{5 5} \mathrm{pg} / \mathrm{ml}$ & P value \\
\hline No. of deliveries & 1258 & 1388 & 302 & \\
\hline Newborns outcomes & & & & \\
Gestational week (week) & $38.6 \pm 1.5$ & $38.5 \pm 1.6$ & $38.5 \pm 1.3$ & NS \\
\hline Preterm birth (\%) & $7.71(97 / 1258)$ & $7.35(102 / 1388)$ & $7.28(22 / 302)$ & NS \\
\hline Very preterm birth (\%) & $0.79(10 / 1258)$ & $1.15(16 / 1388)$ & $0.33(1 / 302)$ & NS \\
\hline Birth weight (kg) & $3.3 \pm 0.5$ & $3.3 \pm 0.5$ & $3.3 \pm 0.5$ & NS \\
\hline Low birth weight (\%) & $4.21(53 / 1258)$ & $5.04(70 / 1388)$ & $4.30(13 / 302)$ & NS \\
\hline Very low birth weight (\%) & $0.16(2 / 1258)$ & $1.01(14 / 1388)$ & $0.33(1 / 302)$ & NS \\
\hline Male new-borns (\%) & $54.05(680 / 1258)$ & $54.68(759 / 1388)$ & $53.97(163 / 302)$ & NS \\
\hline Congenital anomaly (\%) & $0.24(3 / 1258)$ & $0.58(8 / 1388)$ & $0.66(2 / 302)$ & NS \\
\hline PICU attempt (\%) & $2.07(26 / 1258)$ & $3.03(42 / 1388)$ & $4.64(14 / 302)$ & $0.04^{\text {a }}$ \\
\hline Mortality (\%) & $0.08(1 / 1258)$ & $0.36(5 / 1388)$ & $0.33(1 / 302)$ & NS \\
\hline Note: & & & & \\
\hline PICU: pediatric intensive care unit & & & \\
\hline a: a significant difference between the group of E2D <30 pg/ml and $>55 \mathrm{pg} / \mathrm{ml} ;$ & & \\
\hline NS: not significant & & & & \\
\hline
\end{tabular}

\section{Discussion}

This study compared the ovarian performance, pregnancy results, and outcomes of obstetrics and newborns from the patients with an E2D of $<30,30-55,>55 \mathrm{pg} / \mathrm{ml}$. We found that E2D was associated with ovarian stimulation, but did not influence the live-birth rate. The patients with E2D $<30 \mathrm{pg} / \mathrm{ml}$ were less likely to suffer hypertension disorders and their babies had a lower risk for PICU attempt. 
Down-regulation is a common practice in IVF treatment. Previous studies showed that down-regulation with $\mathrm{GnRH}$-a increased the clinical pregnancy rate after IVF; however, this result is obtained from fresh IVF cycles $(2,16)$. In a recent study, we defined E2D $<30 \mathrm{pg} / \mathrm{ml}$ as an over down-regulation, $30-55 \mathrm{pg} / \mathrm{ml}$ as a suitable down-regulation, and $>55 \mathrm{pg} / \mathrm{ml}$ as an insufficient down-regulation, and we found that an over or suitable down-regulation elevated the cumulative pregnancy and live-birth rates (3). Currently, it lacks reports on the effect of down-regulation on obstetrics and pediatrics outcomes.

The result of this study shows that the degree of down-regulation is negatively associated with ovarian stimulation efficiency. With the decrease of E2D, more aggressive and longer stimulation is needed, but the peak E2 level, the number of oocytes and good embryos are lower. When pituitary is aggressively suppressed, its function recovers slower, and more stimulation is needed to initiate follicle-genesis.

Our previous study has demonstrated that a sufficient down-regulation (E2D $\leq 55 \mathrm{pg} / \mathrm{ml}$ ) resulted in a higher cumulative clinical pregnancy rate. The present study showed that the live-birth and miscarriage rates were similar between the patients with E2D $\leq 55$ and $>55 \mathrm{pg} / \mathrm{ml}$. This result can help clinicians in common counselling. Although an insufficient down-regulation (E2D $>55 \mathrm{pg} / \mathrm{ml}$ ) indicates a lower chance of conception, extra concerns about miscarriage is not needed when a clinical pregnancy has been achieved.

Since the first IVF baby (17), the number of children born after IVF has risen rapidly in these 40 years. Globally, there is an increasing attention to the safety of IVF, in terms of obstetrics and perinatal outcomes. However, the results of previous studies are inconsistent. Some studies showed that IVF was a generally safe procedure (18-20). In contrast, some studies found increased risks for newborns or mothers after IVF $(9,21)$. In an IVF treatment, superovulation or culture conditions may contribute to these adverse outcomes (22). Regarding maternal outcomes, we found that E2D was not associated with the occurrence of placenta previa, placenta abruption, premature rupture of membrane, hemorrhage, gestational diabetes mellitus, or intrauterine growth restriction; however, an E2D of $<30 \mathrm{pg} / \mathrm{ml}$ indicated a lower risk for hypertension disorders of pregnancy. The quality of oocytes/embryos may be associated with the pathogenesis of hypertension disorders. Indeed, abnormal cytotrophoblasts cause inadequate remodeling and atherosis of spiral artery, result in ischemia and hypoxia of placenta, which is central to the pathogenesis of this disease (23). Regarding perinatal outcomes, we found that the gestational week, birth weight, sex ratio, congenital anomaly rate, and mortality rate were similar in the patients with different E2D. The babies of patients with an E2D of $<30 \mathrm{pg} / \mathrm{ml}$ were less likely to need PICU treatment. This result indicates that an over down-regulation may benefit follicular recruitment and development, improve embryo/fetus quality, and thus reduce the risk for PICU attempt.

The limitation of this study is its retrospective nature. In addition, only the singleton pregnancy was analyzed. Further study can be performed to confirm these findings.

\section{Conclusions}


We found no effect of down-regulation on cumulative live-birth rate. The patients with E2D $<30 \mathrm{pg} / \mathrm{ml}$ may have advantages in lower risks for maternal hypertension and newborns PICU attempt.

\section{Abbreviations}

IVF: In Vitro Fertilization, E2D: estradiol after down-regulation, PICU: Pediatric Intensive Care Unit, GnRH-a: gonadotropin-releasing hormone-agonist, IRB: Institution Review Board, AFC: antral follicle count, BMI: body mass index.

\section{Declarations}

\section{Ethics approval and consent to participate:}

this study was approved by the Institution Review Board (IRB) of Tongji Hospital. All patients gave the written informed consent for their clinical records to be used in research. Patient information was anonymized before analysis.

\section{Consent for publication:}

all patients signed informed consent regarding publishing their data and photographs.

\section{Availability of data and materials:}

the data are included within the manuscript.

\section{Competing interests:}

there is no conflict of interest.

\section{Funding:}

not applicable

\section{Authors' contributions:}

all authors contributed to the study conception and design. Data collection and analysis were performed by Yu Zheng and Biao Chen. Data interpretation was performed by Xiyuan Dong, Yu Zheng, Biao Chen and Lan Wang. The first draft of the manuscript was written by Xiyuan Dong and all authors commented on previous versions of the manuscript. All authors read and approved the final manuscript. 


\section{Acknowledgements:}

the authors thank all the staff at the Reproductive Medicine Center, Tongji Hospital, for their work and support.

\section{References}

1. Calhaz-Jorge C, Leal F, Cordeiro I, Proenca H, Barata M, Pereira-Coelho AM. Pituitary down-regulation in IVF cycles: is it necessary to use strict criteria? J Assist Reprod Genet. 1995;12:9.

2. Tummon IS, Daniel SA, Kaplan BR, Nisker JA, Yuzpe AA. Randomized, prospective comparison of luteal leuprolide acetate and gonadotropins versus clomiphene citrate and gonadotropins in 408 first cycles of in vitro fertilization. Fertil Steril. 1992;58:3.

3. Zheng Y, Dong X, Wang R, Yang W, Zhang H, Zhu G, et al. The criteria for optimal down-regulation with gonadotropin-releasing hormone-agonist: a retrospective cohort study. Gynecol Endocrinol. 2015;31:12.

4. Vulliemoz NR, McVeigh E, Kurinczuk J. In vitro fertilisation: perinatal risks and early childhood outcomes. Hum Fertil (Camb). 2012;15:2.

5. Chen ZJ, Shi Y, Sun Y, Zhang B, Liang X, Cao Y, et al. Fresh versus Frozen Embryos for Infertility in the Polycystic Ovary Syndrome. N Engl J Med. 2016;375:6.

6. Shi Y, Sun Y, Hao C, Zhang H, Wei D, Zhang Y, et al. Transfer of Fresh versus Frozen Embryos in Ovulatory Women. N Engl J Med. 2018;378:2.

7. Zhu J, Lian Y, Li M, Chen L, Liu P, Qiao J. Does IVF cleavage stage embryo quality affect pregnancy complications and neonatal outcomes in singleton gestations after double embryo transfers? J Assist Reprod Genet. 2014;31:12.

8. Kaser DJ, Melamed A, Bormann CL, Myers DE, Missmer SA, Walsh BW, et al. Cryopreserved embryo transfer is an independent risk factor for placenta accreta. Fertil Steril. 2015;103:5.

9. Fortunato A, Tosti E. The impact of in vitro fertilization on health of the children: an update. Eur $\mathrm{J}$ Obstet Gynecol Reprod Biol. 2011;154:2.

10. Maalouf WE, Mincheva MN, Campbell BK, Hardy IC. Effects of assisted reproductive technologies on human sex ratio at birth. Fertil Steril. 2014;101:5.

11. Li Z, Wang YA, Ledger W, Sullivan EA. Birthweight percentiles by gestational age for births following assisted reproductive technology in Australia and New Zealand, 2002-2010. Hum Reprod. 2014;29:8.

12. Bu Z, Chen ZJ, Huang G, Zhang H, Wu Q, Ma Y, et al. Live birth sex ratio after in vitro fertilization and embryo transfer in China-an analysis of 121,247 babies from 18 centers. PLoS One. 2014;9:11.

13. Davies MJ, Moore VM, Willson KJ, Van Essen P, Priest K, Scott H, et al. Reproductive technologies and the risk of birth defects. N Engl J Med. 2012;366:19.

14. Huang B, Qian K, Li Z, Yue J, Yang W, Zhu G, et al. Neonatal outcomes after early rescue intracytoplasmic sperm injection: an analysis of a 5-year period. Fertil Steril. 2015;103:6. 
15. Zegers-Hochschild F, Adamson GD, de Mouzon J, Ishihara O, Mansour R, Nygren $\mathrm{K}$, et al. International Committee for Monitoring Assisted Reproductive Technology (ICMART) and the World Health Organization (WHO) revised glossary of ART terminology, 2009. Fertil Steril. 2009;92:5.

16. Antoine JM, Salat-Baroux J, Alvarez S, Cornet D, Tibi C, Mandelbaum J, et al. Ovarian stimulation using human menopausal gonadotrophins with or without LHRH analogues in a long protocol for invitro fertilization: a prospective randomized comparison. Hum Reprod. 1990;5:5.

17. Steptoe PC, Edwards RG. Birth after the reimplantation of a human embryo. Lancet. 1978;2:8085.

18. Yan J, Huang G, Sun Y, Zhao X, Chen S, Zou S, et al. Birth defects after assisted reproductive technologies in China: analysis of 15,405 offspring in seven centers (2004 to 2008). Fertil Steril. 2011;95:1.

19. Yin L, Hang F, Gu LJ, Xu B, Ma D, Zhu GJ. Analysis of birth defects among children 3 years after conception through assisted reproductive technology in China. Birth Defects Res A Clin Mol Teratol. 2013;97:11.

20. Levi Setti PE, Albani E, Morenghi E, Morreale G, Delle Piane L, Scaravelli G, et al. Comparative analysis of fetal and neonatal outcomes of pregnancies from fresh and cryopreserved/thawed oocytes in the same group of patients. Fertil Steril. 2013;100:2.

21. Maheshwari A, Kalampokas T, Davidson J, Bhattacharya S. Obstetric and perinatal outcomes in singleton pregnancies resulting from the transfer of blastocyst-stage versus cleavage-stage embryos generated through in vitro fertilization treatment: a systematic review and meta-analysis. Fertil Steril. 2013;100:6.

22. Wilkins-Haug L. Epigenetics and assisted reproduction. Curr Opin Obstet Gynecol. 2009;21:3.

23. Rana S, Lemoine E, Granger JP, Karumanchi SA. Preeclampsia: Pathophysiology, Challenges, and Perspectives. Circ Res. 2019;124:7.

\section{Figures}




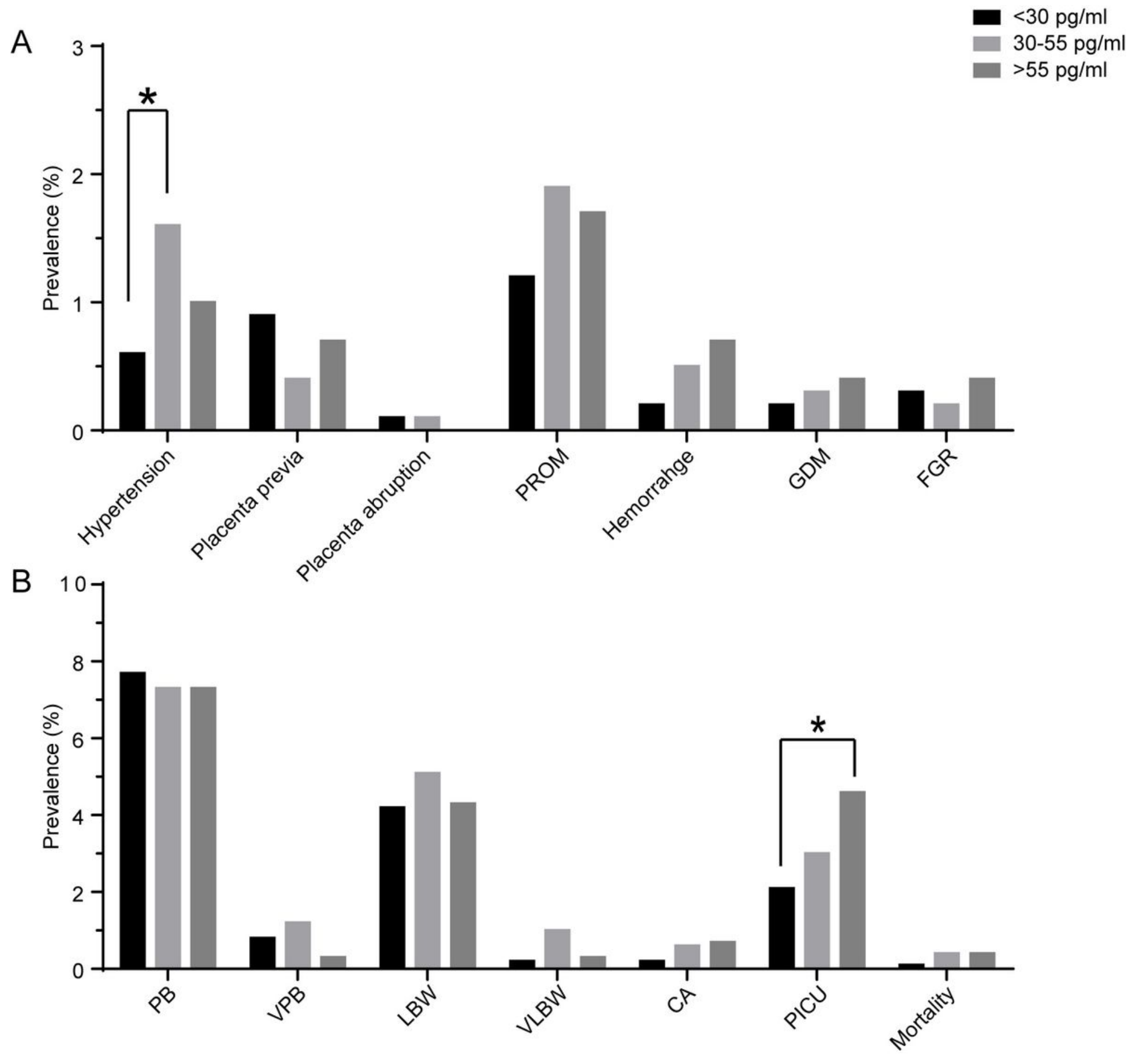

Figure 1

The maternal complications and perinatal outcomes of the patients according to E2D A: maternal complications of patients with E2D $<30,30-55,>55 \mathrm{pg} / \mathrm{ml}$; B: perinatal outcomes of patients with E2D $<30,30-55,>55$ pg/ml; PROM: premature rupture of membranes; GDM: gestational diabetes mellitus; FGR: fetal growth restriction; PB: preterm birth; VPB: very preterm birth; LBW: low birth weight; VLBW: very low birth weight; $\mathrm{CA}$ : congenital anomaly; PICU: pediatric intensive care unit 